\title{
Analysis of an energy pile enduring cyclic temperature loads
}

\section{Zhong-jin Wang PhD}

School of Civil Engineering and Architecture, Ningbo Institute of

Technology, Zhejiang University, Ningbo, China; Zcone High-tech Pile

Industry Holdings Co., Ltd, Ningbo, China; Research Center of Coastal and

Urban Geotechnical Engineering, Zhejiang University, Hangzhou, China

(corresponding author: zhongjin_wang@zju.edu.cn)

(Orcid:0000-0001-6765-3098)

Ri-hong Zhang PhD

Zcone High-tech Pile Industry Holdings Co., Ltd, Ningbo, China

(Orcid:0000-0002-2461-9233)

\author{
Peng-fei Fang PhD \\ Ningbo Institute of Technology, Zhejiang University, Ningbo, China \\ Wen-jun Wang PhD \\ Ningbo Institute of Technology, Zhejiang University, Ningbo, China \\ Heng-yu Wang PhD \\ Ningbo Institute of Technology, Zhejiang University, Ningbo, China
}

Based on the conclusion that the effect of normal pressure on temperature distribution and the effect of temperature on soil-concrete interface friction are negligible, the finite-element model was established to analyse the characteristics of a pile enduring cyclic temperatures, adopting the sequential thermal coupling method. The temperature-induced additional displacements and axial forces along the pile depth were analysed, and the influences of temperature on the additional axial force distribution of the energy pile were analysed with different pile head loads. The analysis results showed that cyclic heating and natural cooling will lead to additional axial pile forces and displacements along the pile depth. It was concluded that loads applied at the energy pile top should not be heavier than the value at which plastic deformation at the pile end soil would be initiated and at which nonlinear pile top settlement occurred.

\section{Notation}

$C_{\text {pile }} \quad$ specific heat of the pile

$C_{\text {soil }} \quad$ specific heat of the soil

$c_{\text {soil }}$ soil cohesion

$E_{\text {pile }} \quad$ elastic modulus of the pile

$E_{\text {soil }} \quad$ elastic modulus of the soil

$\alpha l_{\text {pile }} \quad$ linear expansion coefficient of the pile

$\alpha l_{\text {soil }} \quad$ linear expansion coefficient of the soil

$\gamma_{\text {pile }} \quad$ pile density

$\gamma_{\text {soil }}$ soil density

$\lambda_{\text {pile }}$ pile conductivity

$\lambda_{\text {soil }}$ soil conductivity

$v_{\text {pile }} \quad$ Poisson's ratio of the pile

$v_{\text {soil }} \quad$ Poisson's ratio of the soil

$\Phi_{\text {soil }} \quad$ friction angle of the soil

\section{Introduction}

Piles, as one of the most widely used foundations for enhancing the bearing capacity of soil, have been studied by many scholars in the past decades. Many theoretical and experimental researches also have been conducted to analyse their bearing characteristics due to their extensive applications in practical engineering (Castelli and Maugeri, 2002; Wang et al., 2012; Zhang et al., 2018). In recent years, as an innovative use, energy piles have been used increasingly due to their advantages of economic benefits and environment-friendliness, coupling the role of structural foundations to that of heat exchangers to exploit the large thermal storage capabilities of the ground (Brandl, 2006; Laloui and Di Donna, 2013; Mimouni and Laloui, 2015; Zarrella et al., 2017).
Field measurements have been carried out to investigate the changes in the bearing characteristics of piles due to temperature, such as the axial forces along the pile depth, the displacements at the pile head and the pile side frictional resistance (Akrouch et al., 2014; Amatya et al., 2012; Hemmingway and Long, 2013; Laloui et al., 2006; Suryatriyastuti et al., 2012). In situ heating tests usually applied a temperature increase of about $21-22^{\circ} \mathrm{C}$, inducing concrete thermal responses, such as expansions and stresses, and pile displacement. The measurement results showed that the temperature applied at the pile could lead to additional thermal stresses and displacements and even cause significant thermal deformation and stress in the pile. Some test results also showed that additional thermal stresses mobilised in the pile during the heating and cooling processes had been subjected to restraint conditions (Murphy et al., 2014; Saggu and Chakraborty, 2015). Model tests were also carried out to examine the heat transfer performance and bearing characteristics of energy piles (Kong et al., 2017, 2019; Wang et al., 2016, 2019), and it was concluded that cyclic heating-cooling temperatures could lead to thermal strain and stress in the pile shaft. The finite-element method remains one of the most widely used methods to simulate energy piles subjected to superstructure loads and seasonally cyclic thermal loads over several years, and the results from analyses have shown that the finite-element method is a very effective means to simulate the changes in energy pile characteristics (Di Donna et al., 2016; Wang et al., 2019; Yavari et al., 2014). Other numerical methods have also been used to analyse the variations in pile stresses and settlements during the heating and cooling processes, obtaining some similar conclusions (Di Donna and Laloui, 2015; Zarrella et al., 2017; Zhang et al., 2017; 
Zhou et al., 2018). A review of existing studies about energy piles evidenced that there have been many studies mainly about thermal performance, assessing the potential of heat production and storage through energy pile foundations. Studies about the pile bearing and deformation characteristics with thermomechanical coupling were relatively few. Although energy piles have been widely used for more than a few decades, many mechanistic questions need to be studied, such as additional settlements and stresses while the piles endure the cyclic heating and cooling temperatures.

Through the preceding description of existing studies, it can be seen that both thermal-induced displacements and stresses must be taken into account in the geotechnical design of energy piles. The variations in the bearing characteristics of energy piles, such as additional displacements, axial force and pile shaft friction resistance along the pile depth, are complex, being closely related to the site's engineering geological conditions. In this paper, in order to obtain the characteristics of a single energy pile at cyclic heating-cooling temperatures, the finite-element model was established to analyse the characteristics of a single energy pile at different pile head load levels, based on the conclusion obtained by Wang et al. (2019) that the effects of temperature on soil-concrete interface friction and the effects of normal pressure on temperature distribution are negligible. The analysed results showed that the levels of pile head load have significant effects on the bearing characteristics of energy piles. It was concluded that loads applied at the energy pile head should not be heavier than the value at which plastic deformation at the pile end soil would be initiated and at which non-linear pile head settlement occurred. The analysis results could provide a theoretical basis for related projects on predicting the characteristics of energy piles.

\section{The finite-element model}

Wang et al. (2019) concluded that the distributions of temperature with different normal pressures have no significant difference and the temperature also has no obvious effects on the frictional resistances at the concrete-soil interface. The measurement results from laboratory experiments carried out by Wang et al. (2019) also showed that the temperature at the concrete-soil interface increases with time and tends to be constant after heating for a certain time. Based on the results mentioned earlier, an asymmetrical finite-element model was established to simulate an energy pile with embedded spiral tubes, as shown in Figure 1.

The calculation diagram and element partition are shown in Figure 2. The diameter of the energy pile is $1000 \mathrm{~mm}$, and the length of the pile is $40 \mathrm{~m}$, the soil depth is $80 \mathrm{~m}$ in the direction of the pile depth, and the width value is $40 \mathrm{~m}$. The effect of the liquid flow on the temperature distribution in the heating pipe was neglected, and the influence of temperature change on the mechanical properties of the contact interface was also not considered. The finite-element analysis adopted the sequential thermomechanical coupling method. The implication of this method is that stress does not affect temperature distribution, but

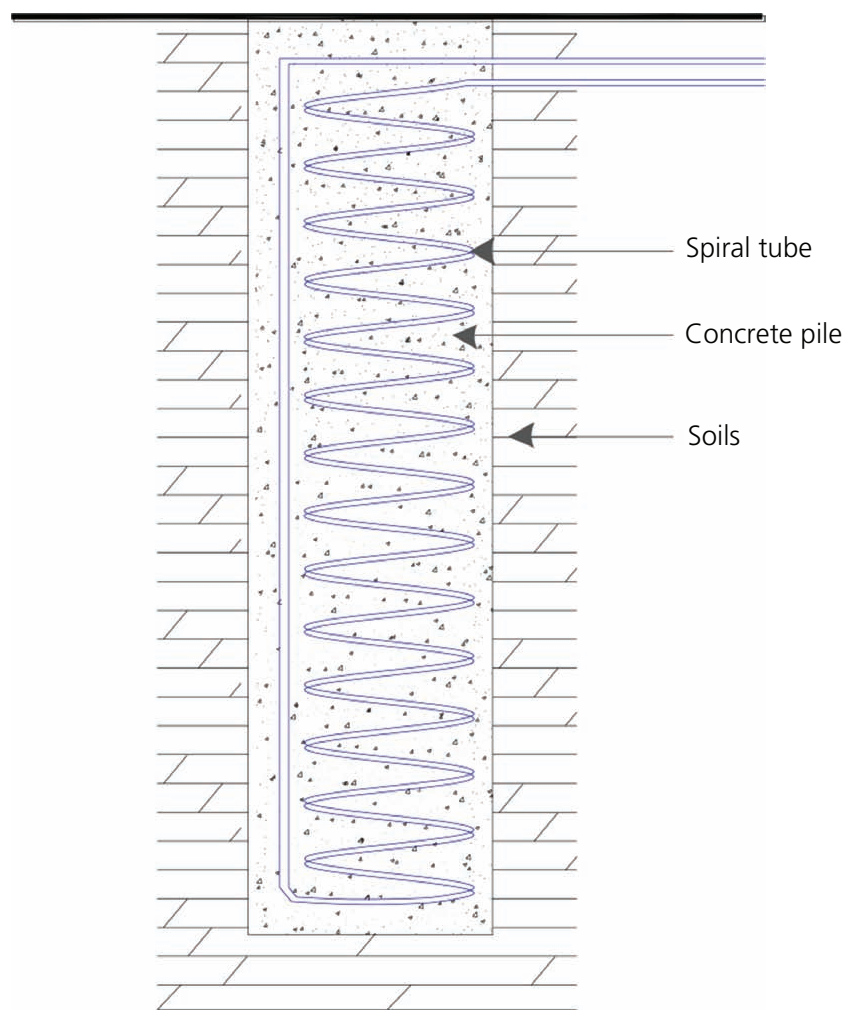

Figure 1. Simplified diagram of spiral pipes in a pile

temperature causes stress changes. In the process of heatconduction analysis, heat-conduction elements were adopted, and three-dimensional stress elements were adopted in the process of coupled thermomechanical analysis. The pile adopted the elastic model and the soil adopted the Mohr-Coulomb elastoplasticity model in the process of coupled thermomechanical analysis.
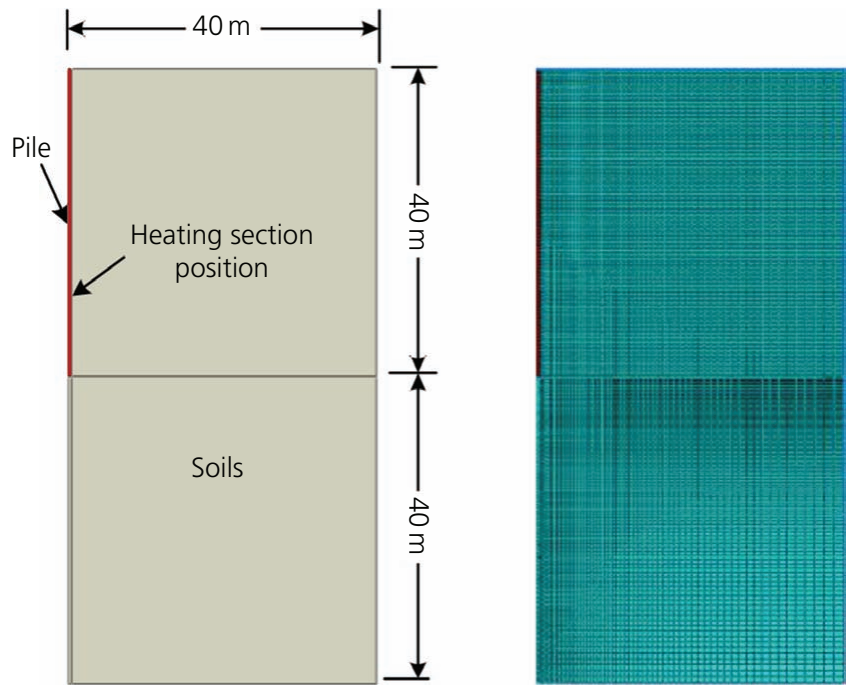

Figure 2. Simplified diagram and elements for the calculation model 
Table 1. Parameters of finite-element model

$\begin{array}{lclc}\text { Parameter } & \text { Value } & \text { Parameter } & \text { Value } \\ E_{\text {pile }}: \mathrm{GPa} & 30 & \mathrm{C}_{\text {soil }}: \mathrm{J} /(\mathrm{kg} \mathrm{K}) & 1305 \\ E_{\text {soil }}: \mathrm{MPa} & 20 & \gamma_{\text {pile }}: \mathrm{kN} / \mathrm{m}^{3} & 25 \\ \alpha \text { pile: }^{\circ}{ }^{\circ} \mathrm{C}^{-1} & 1 \times 10^{-5} & \gamma_{\text {soill }}: \mathrm{kN} / \mathrm{m}^{3} & 20 \\ \alpha l_{\text {soil }}:{ }^{\circ} \mathrm{C}^{-1} & 6 \times 10^{-6} & \gamma_{\text {pile }} & 0.15 \\ \lambda_{\text {pile }}: \mathrm{W} /(\mathrm{m} \mathrm{K}) & 1.74 & \text { V }_{\text {soil }} & 0.35 \\ \lambda_{\text {soil }}: \mathrm{W} /(\mathrm{m} \mathrm{K}) & 1.16 & C_{\text {soil }}: \mathrm{kPa} & 5 \\ C_{\text {pile }}: J /(\mathrm{kg} \mathrm{K}) & 1706 & \Phi_{\text {soil: }}{ }^{\circ} & 30\end{array}$

The calculation parameters of the model adopted the values recommended by the 'Code for design of concrete structures' (GB 50010-2010 (SAC, 2010)) and 'Thermal design code for civil buildings' (GB 50176-93 (SAC, 1993)) and the literature (Thompson, 2013). For the related parameters, Rotta Loria and Laloui (2016) suggested taking the ratio of expansion coefficient of the pile to that of the soil as $0 \cdot 25-4 \cdot 0$. The heating surfaces were assumed to be at the interface between the pile and surrounding soil, ignoring the effects of fluid flow on the change in temperature. The calculation parameters of the model are shown in Table 1.

$E_{\text {pile }}$ is the pile's elastic modulus, $E_{\text {soil }}$ is the soil's elastic modulus, $\alpha l_{\text {pile }}$ is the pile's linear expansion coefficient, $\alpha l_{\text {soil }}$ is the soil's linear expansion coefficient, $\lambda_{\text {pile }}$ is the pile's conductivity, $\lambda_{\text {soil }}$ is the soil's conductivity, $C_{\text {pile }}$ is the pile's specific heat, $C_{\text {soil }}$ is the soil's specific heat, $\gamma_{\text {pile }}$ is the pile's density, $\gamma_{\text {soil }}$ is the soil's density, $v_{\text {pile }}$ is the pile's Poisson's ratio, $v_{\text {soil }}$ is the soil's Poisson's ratio, $c_{\text {soil }}$ is soil cohesion and $\Phi_{\text {soil }}$ is the friction angle of the soil.

According to relevant experimental test data (Laloui et al., 2006; Li et al., 2016; Thompson, 2013), the overall temperature of the pile increased by about $20^{\circ} \mathrm{C}$ after the energy pile had been heated for a certain period of time, and the measured soil temperature at a certain depth below the ground was $17 \cdot 5-22 \cdot 5^{\circ} \mathrm{C}$ (Gui and Cheng, 2014; Li et al., 2016). In the Ningbo region of China, the measured soil temperature at $10 \mathrm{~m}$ depth below the ground was $18 \cdot 4-20 \cdot 4^{\circ} \mathrm{C}$.

The initial temperature of the aforementioned model adopted was regarded as $20^{\circ} \mathrm{C}$. After heating, the increase in temperature was set to be $18^{\circ} \mathrm{C}$. The temperature load was applied according to the actual increase from the laboratory test result obtained by Wang et al. (2019). The calculation model adopted the sequential thermocoupling analysis method. In the thermal analysis process, the heat-transfer element was adopted, and the asymmetrical stress element is used in the coupling analysis process. The bottom and the sides of the model were fixed, and the top was unconstrained. The application of cyclic temperatures takes place in the following steps: applying a temperature load for $12 \mathrm{~h}$ and then natural cooling for $12 \mathrm{~h}$. The application of temperature agrees with the actual increase from the laboratory, neglecting the change in temperature at the interface while applying a temperature load after natural cooling.

\section{Analysis of temperature conduction}

The distribution of temperature in the soil along the pile's radial direction is shown in Figure 3. It can be seen from Figure 3(a) that, as the heating time increases, the temperature gradually increases in the soil and decreases obviously along with distance. The distribution curve of temperature in the soil along the pile's radial direction is consistent with the relevant measured data (Qian, 2017). The distributions of temperature along the pile's radial direction also decrease obviously along with distance and the temperature distribution in the pile has no obvious differences after heating for 10,20 and $27 \mathrm{~d}$. The distribution of the temperature in the soil along the pile's radial direction after $27 \mathrm{~d}$ of cyclic heating and cooling and then natural cooling for $60 \mathrm{~d}$ is shown in Figure 3(b).

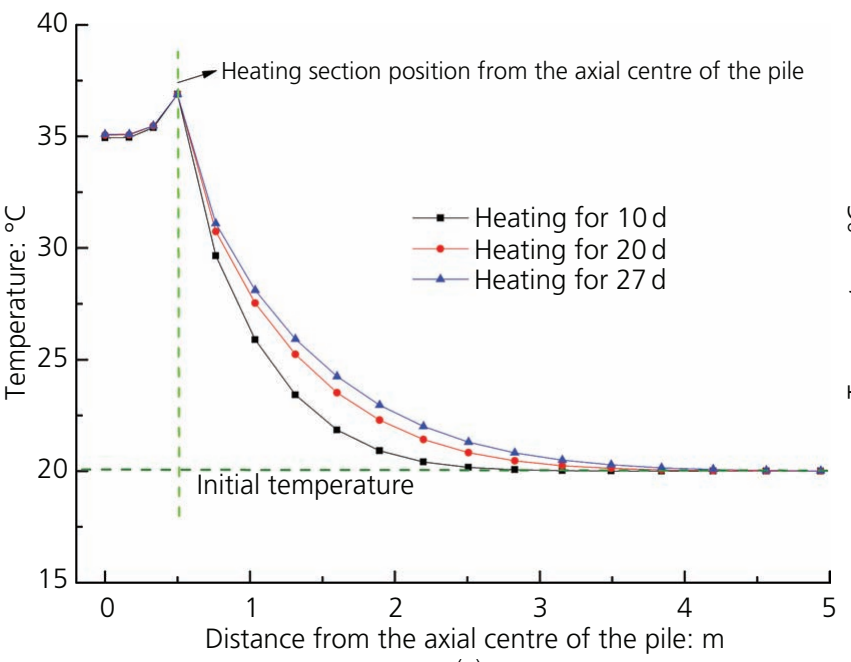

(a)

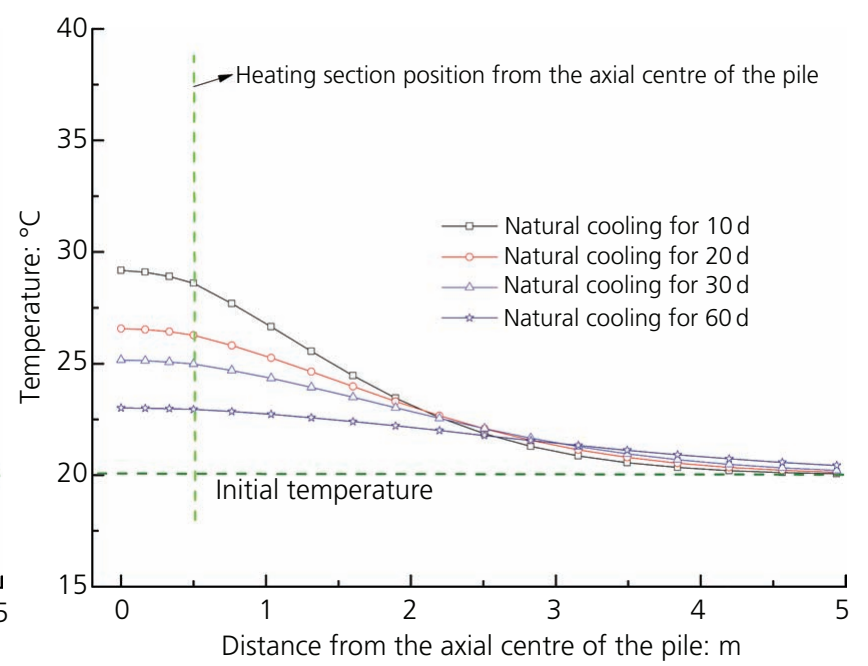

(b)

Figure 3. The distribution of temperature in the soil along the pile's radial direction: (a) heating condition; (b) cooling condition 
From the curve in Figure 3(b), it can be seen that cooling of the soil and the pile needs a longer time than that required for heating.

During the cooling process, the soil temperature continued to rise relative to the original state up to a distance of about $2.5 \mathrm{~m}$ away from the heating position, as shown in Figure 3(b). This may be because the temperature in the soil outside this region is lower than the temperature in the soil region that is obviously heated. From Figure 3(b), it also can be seen that the cooling of temperature in the soil is more obvious than that in the pile. The analysis of the field test data also obtained the same conclusion (Gui and Cheng, 2014; Li et al., 2016; Lu et al., 2017).

\section{Changes in bearing characteristics of the energy pile}

Many scholars have concluded that bearing characteristics are related to the pile top load (Gui and Cheng, 2014; Li et al., 2016; $\mathrm{Lu}$ et al., 2017). The load-settlement curves from the finiteelement calculated model are shown in Figure 4, and the knee of the load-settlement curve appeared for the pile top load of about $4700 \mathrm{kN}$. When the pile top load is less than $4700 \mathrm{kN}$, the pile top and pile end settlements are linear as the applied pile top load increases. The changes in pile top displacements while the pile is subjected to cyclic temperatures for $27 \mathrm{~d}$ are shown in Figure 5.

From Figure 5(a), it can be seen that the additional pile top displacements appear to be cyclically changing while the pile endures cyclic temperatures and the additional displacement changes are closely related to the level of pile top loads. When the pile top loads are equal to 1000 and $3000 \mathrm{kN}$, the additional pile displacements are almost identical to the change in displacements when the pile head had no load. The additional displacements at the pile head decrease when the pile head loads are equal to 5000 and $6000 \mathrm{kN}$. The additional pile head displacements almost have no change after enduring cyclic

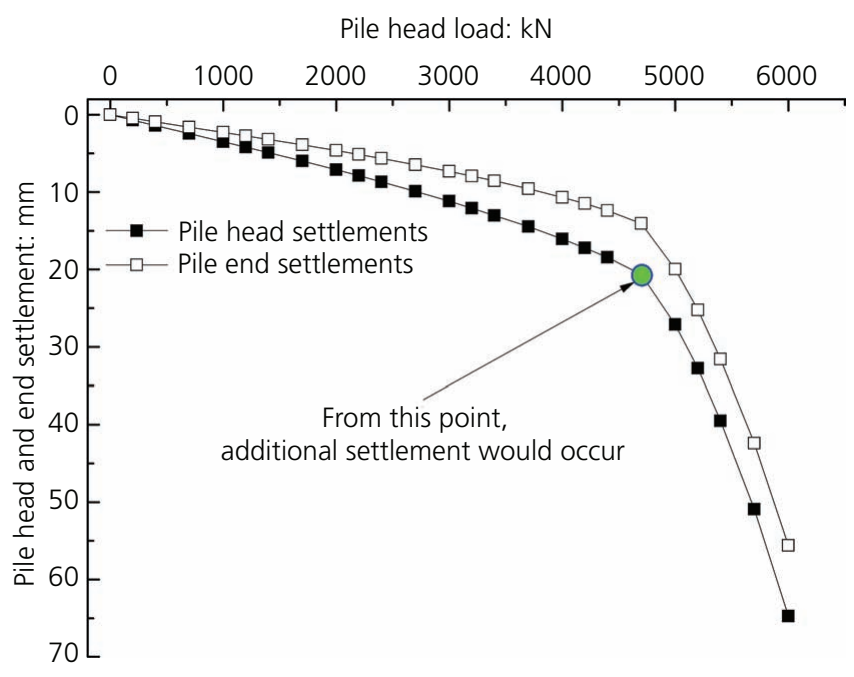

Figure 4. Load-displacement curves of the pile temperatures for $10 \mathrm{~d}$ at different pile head load levels, as seen in Figure 5. In order to simplify the analysis and save computing time, only $10 \mathrm{~d}$ cyclic temperatures are considered to study the effects of cyclic temperature loads on the bearing characteristics of energy piles. The effects of temperature on the top and end displacements of pile are shown in Figure 5(b). It can be seen that the additional pile head and end displacements have no obvious difference when the pile head loads are equal to 1000 and $3000 \mathrm{kN}$. As the pile head load increases to more than $5000 \mathrm{kN}$, the additional pile head load displacements decrease, and the additional pile end settlements increase with increasing pile head loads. From Figure 5(b), it can be seen that, as the pile head load increases, particularly to more than $5000 \mathrm{kN}$, the additional pile settlements cannot return to the original state, because of the plastic settlements that have occurred when the pile head load increased to a value of about $4700 \mathrm{kN}$, as shown in Figure 4.

As discussed earlier, it was concluded that cyclic heating and cooling would lead to additional displacements when heavy loads are applied at the energy pile top, at which non-linear settlements began to occur, and from the view of engineering safety, loads applied at the energy pile top should not be heavier than the value at which non-linear settlements began to occur. Within the load range mentioned earlier, the displacement of the energy pile caused by heating could be eliminated with the process of natural cooling, as shown in Figure 5(b).

The displacement differences between the pile top and end caused by cyclic temperatures for $10 \mathrm{~d}$ and natural cooling for $30 \mathrm{~d}$ are shown in Figure 6. It can be seen from Figure 6 that the displacement differences of the energy pile caused by cyclic heating for $10 \mathrm{~d}$ and natural cooling for $30 \mathrm{~d}$ were similar, with minute differences as the pile head load increases.

The additional axial force caused by temperature along the pile depth is shown in Figure 7. It can be seen from Figure 7 that the loads at the pile top had a great influence on additional pile axial forces due to temperature. The pile head load increases to a value that could lead to the pile end settlement suddenly increasing; the relative displacement of the pile and surrounding soil increases, the side friction resistance is nearly fully developed and the axial force caused by temperature is significantly reduced. As the pile top loads increase, the additional maximum pile axial force caused by the temperature reduces.

When the load at pile top is less than $4700 \mathrm{kN}$, the maximum change in the pile axial force caused by heating is at approximately $25 \mathrm{~m}$ below pile top. When the loads at the pile head are larger than $5000 \mathrm{kN}$, the maximum changes in the energy pile axial force due to heating reduce with the increase in pile head loads, and the corresponding positions of the maximum changes in the axial force rise up along the pile depth with increase in the pile top load. After heating for $10 \mathrm{~d}$, the energy pile begins to cool naturally for $30 \mathrm{~d}$, and the change in pile axial forces gradually returns to the original state when pile top loads are less than $4700 \mathrm{kN}$. When the pile top 


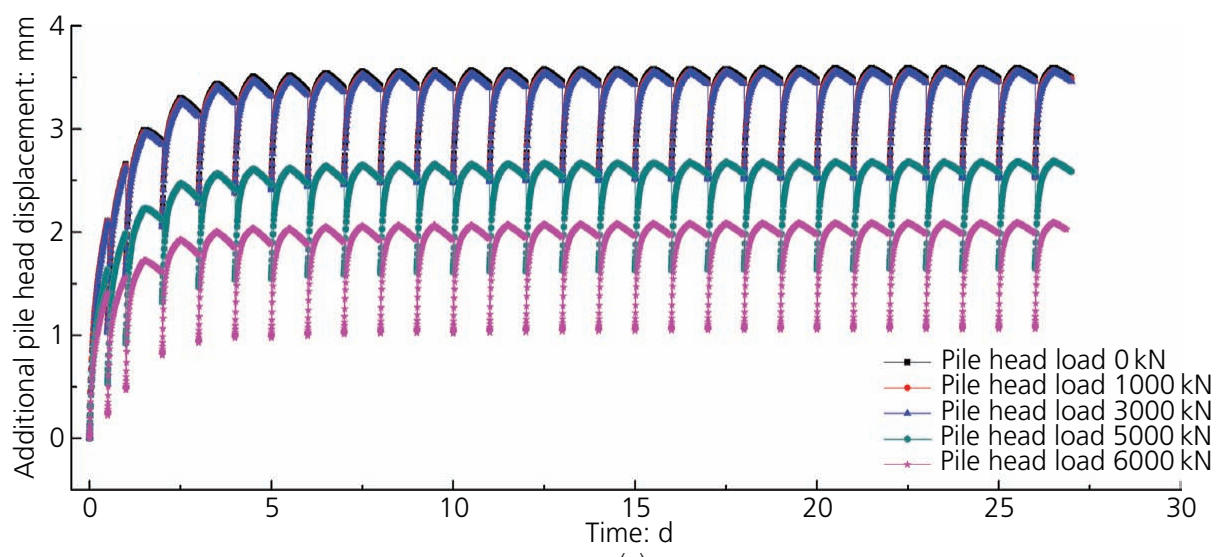

(a)

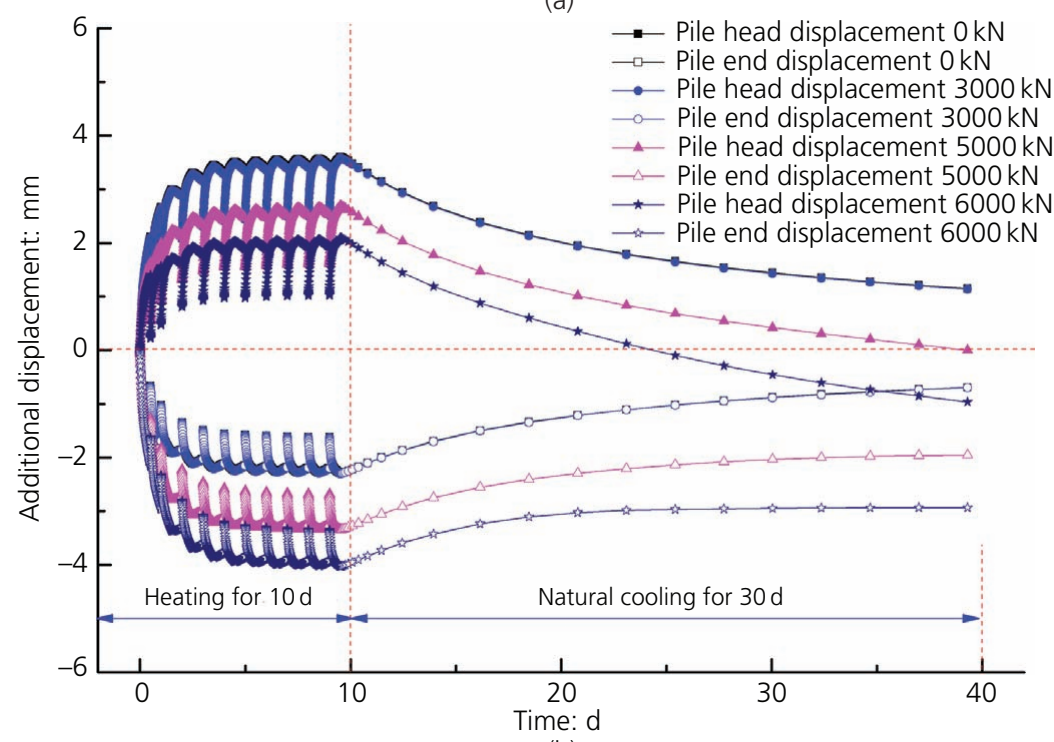

(b)

Figure 5. Additional displacements caused by temperature: (a) heating and cooling circulation for $30 \mathrm{~d}$ and (b) a cycle of heating for $10 \mathrm{~d}$ and cooling for $30 \mathrm{~d}$

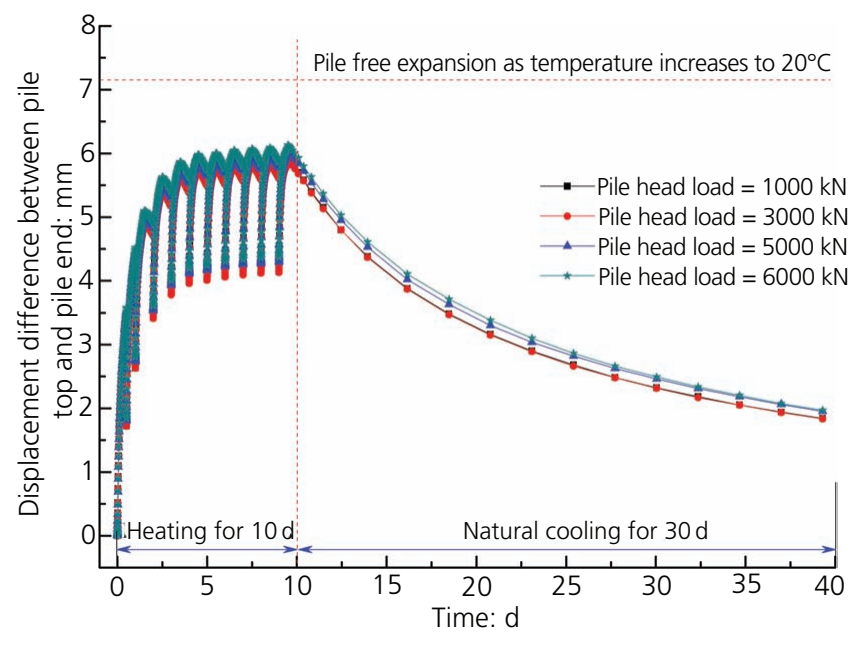

Figure 6. Differences in additional displacements caused by cyclic temperatures

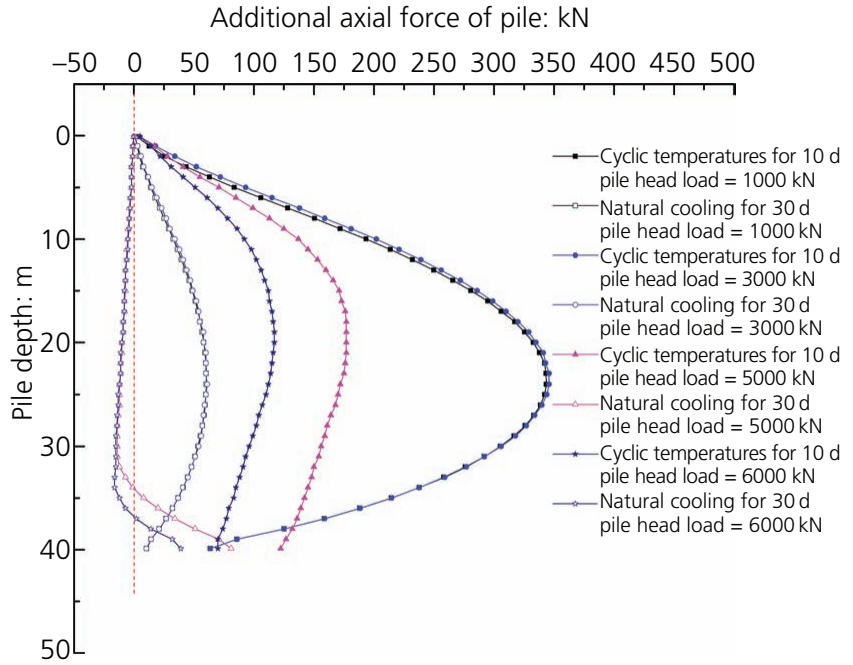

Figure 7. Additional pile axial forces caused by temperature 


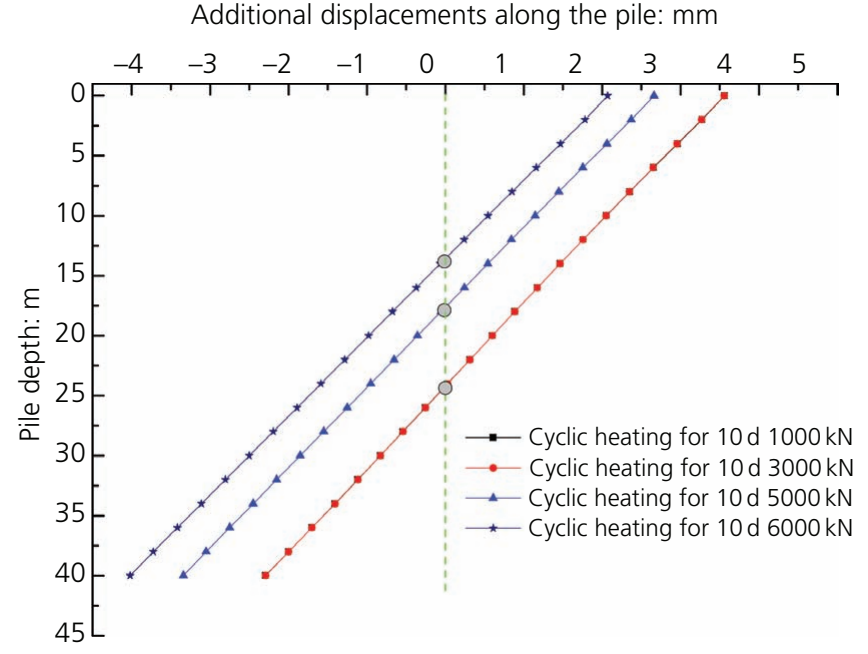

(a)

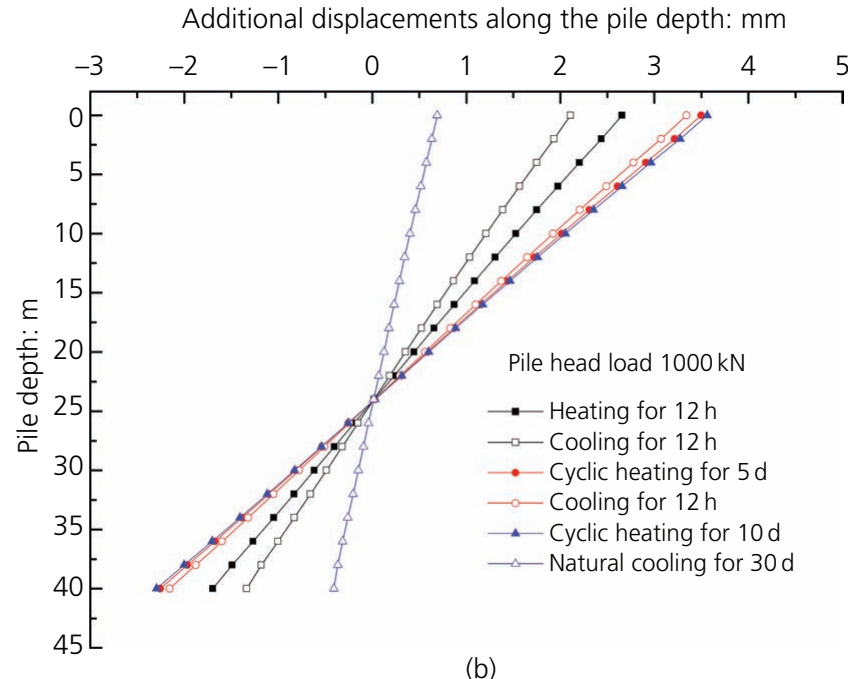

(b)

Figure 8. Additional temperature-induced displacements along the pile depth. (a) Additional displacement at different pile loads, (b) zero point of additional displacement

loads are larger than $4700 \mathrm{kN}$, the change in the pile axial force is gradually restored at the upper part of the pile, but the changes at the lower part of the pile are obvious at the higher pile top load level, as shown in Figure 7.

The additional displacements along the pile depth caused by cyclic heating and natural cooling are shown in Figure 8. It can be seen that the additional displacements along the pile depth are linear with different pile head loads and there is a zero point (neutral point) at which the additional displacement caused by temperature is zero as shown in Figure 8(a). From the neutral point, the direction of the additional displacements caused by temperature load is opposite. When the pile head load is not heavier than the value that could lead to non-linear settlement of the pile top as shown in Figure 4, the change zero point is almost identical as shown in Figure 8(b) when the pile head loads are equal to 1000 and $3000 \mathrm{kN}$. It can be seen from Figures 5 and 6 that, when the pile head loads reach the value at which the pile end settlement suddenly increases, the additional displacements along the pile depth are unable to return to the initial conditions, which is quite different from what happens when light loads are applied to the pile head. The additional displacements along the pile depth caused by cyclic temperature and natural cooling when the pile head load is equal to $1000 \mathrm{kN}$ are shown in Figure 8(b). From Figure $8(\mathrm{~b})$, it can be seen that the additional displacements along the pile depth progressively increase as cyclic temperatures are applied to the pile. After cooling for $12 \mathrm{~h}$, the additional displacements along the pile depth are partially recovered, similar to those when the pile was heated for $12 \mathrm{~h}$ and $5 \mathrm{~d}$. After natural cooling for $30 \mathrm{~d}$, the additional displacements along the pile depth are almost recovered with a pile head load of $1000 \mathrm{kN}$.

As discussed earlier, it can be seen that cyclic heating and natural cooling would lead to additional axial pile forces and displacements along the pile depth. When the loads applied to the energy piles were sufficiently heavy that non-linear settlements began to occur, the additional settlements could not be dissolved. The additional displacements and axial pile forces along the pile depth appear to have different characteristics with different pile head load levels. From the view of engineering safety, loads applied at the energy pile top should not be heavier than the value at which non-linear settlement occurred. Within the load range mentioned earlier, the displacement of the energy pile caused by heating could be eliminated with the process of cooling and the neutral point was invariable, as shown in Figure 8(b).

\section{Conclusions}

As discussed earlier, the following are the main conclusions of this paper.

- Cyclic heating and cooling would lead to additional displacements and axial forces along the pile depth. The additional displacements and axial pile forces along the pile depth appear to have different characteristics with changed pile head load levels.

- With heavy loads at which non-linear settlement occurred on the load-settlement curve, irrecoverable settlement would occur in the process of cyclic heating and cooling. For engineering safety, loads applied at the energy pile top should not be heavier than the value at which non-linear settlement occurred.

- The displacements differences between the pile top and end caused by heating and cooling are approximately consistent at different load levels. The displacements of the energy pile caused by heating could be eliminating with the process of cooling when the applied pile head load is at a lower load level.

- The neutral point of additional displacements is invariable at a lower load level. 


\section{Acknowledgements}

This research was supported by the National Natural Science Foundation of China (research grant number 51708496), the Zhejiang Provincial Natural Science Foundation (research grant numbers LY16E080010 and No. LY19E080013) and the Research Project of Zhejiang Provincial Education Department (number Y201636901). These financial supports are gratefully acknowledged.

\section{REFERENCES}

Akrouch GA, Sánchez M and Briaud J (2014) Thermo-mechanical behavior of energy piles in high plasticity clays. Acta Geotechnica 9(3): 399-412, https://doi.org/10.1007/s11440-014-0312-5.

Amatya BL, Soga K, Bourne-Webb PJ, Amis T and Laloui L (2012) Thermo-mechanical behaviour of energy piles. Géotechnique 62(6): 503-519, https://doi.org/10.1680/geot.10.P.116.

Brandl H (2006) Energy foundations and other thermo-active ground structures. Géotechnique 56(2): 81-122, https://doi.org/10.1680/geot. 2006.56.2.81

Castelli F and Maugeri M (2002) Simplified nonlinear analysis for settlement prediction of pile groups. Journal of Geotechnical and Geoenvironmental Engineering 128(1): 76-84.

Di Donna A and Laloui K (2015) Numerical analysis of the geotechnical behaviour of energy piles. International Journal for Numerical and Analytical Methods in Geomechanics 39(8): 861-888.

Di Donna A, Rotta Loria AF and Laloui L (2016) Numerical study of the response of a group of energy piles under different combinations of thermo-mechanical loads. Computers and Geotechnics 72: 126-142, https://doi.org/10.1016/j.compgeo.2015.11.010.

Gui S and Cheng X (2014) In-situ tests on structural responses of energy piles during heat exchanging process. Chinese Journal of Geotechnical Engineering 36(6): 1087-1094, https://oi.org/10.11779/ CJGE201406014.

Hemmingway P and Long M (2013) Energy piles: site investigation and analysis. Proceedings of the Institution of Civil Engineers Geotechnical Engineering 166(6): 561-575, https://doi.org/10.1680/ geng. 12.00075 .

Kong G, Wang C, Liu H, Wu D and Che P (2017) Analysis of pile head displacement of energy pile under repeated temperature cycling. Rock and Soil Mechanics 38(4): 958-964, https://doi.org/10.16285/j.rsm. 2017.04.005.

Kong GQ, Wu D, Liu HL et al. (2019) Performance of a geothermal energy deicing system for bridge deck using a pile heat exchanger. International Journal of Energy Research 43(1): 596-603, https://doi. org/10.1002/er.4266.

Laloui L and Di Donna A (2013) Energy Geostructures: Innovation in Underground Engineering. Wiley-ISTE, London, UK.

Laloui L, Nuth M and Vulliet L (2006) Experimental and numerical investigations of the behaviour of a heat exchanger pile. International Journal for Numerical and Analytical Methods in Geomechanics 8(30): 763-781, https://doi.org/10.1002/nag.499.

Li X, Guo H and Cheng X (2016) Experimental and numerical study on temperature distribution in energy piles. China Civil Engineering Journal 2016(4): 102-110, https://doi.org/10.15951/j.tmgcxb.2016.04.011.

Lu H, Jiang G, Wang $\mathrm{H}$ et al. (2017) In-situ tests and thermo-mechanical bearing characteristics of friction geothermal energy piles. Chinese Journal of Geotechnical Engineering 39(2): 334-342, https://doi.org/ 10.11779/CJGE201702018.

Mimouni T and Laloui L (2015) Behaviour of a group of energy piles. Canadian Geotechnical Journal 52(12): 1913-1929, https://doi.org/10. 1139/cgj-2014-0403.

Murphy KD, McCartney JS and Henry KS (2014) Thermo-mechanical characterization of a full-scale energy foundation. In From Soil Behaviour Fundamentals to Innovations in Geotechnical Engineering: Honoring Roy E. Olson (Iskander M, Garlanger JE and Hussein MH (eds)). American Society of Civil Engineers, Reston, VA, USA, GSP 233, pp. 617-628.

Qian F (2017) Study on the Bearing Capacity of Heat Exchanger Piles Considering Pile-Soil Interaction. MS thesis, Ningbo University, Ningbo, China.

Rotta Loria AF and Laloui L (2016) The interaction factor method for energy pile groups. Computers and Geotechnics 80: 121-137, https:// doi.org/10.1016/j.compgeo.2016.07.002.

SAC (Standardization Administration of China) (1993) GB 50176-93: Thermal design code for civil buildings. SAC, Beijing, China.

SAC (2010) GB 50010-2010: Code for design of concrete structures. SAC, Beijing, China.

Saggu R and Chakraborty T (2015) Cyclic thermo-mechanical analysis of energy piles in sand. Geotechnical and Geological Engineering 33(2): 321-342, https://doi.org/10.1007/s10706-014-9798-8.

Suryatriyastuti ME, Mroueh H and Burlon S (2012) Understanding the temperature-induced mechanical behaviour of energy pile foundations. Renewable and Sustainable Energy Reviews 16(5): 3344-3354, https:// doi.org/10.1016/j.rser.2012.02.062.

Thompson WH III (2013) Numerical Analysis of Thermal Behavior and Fluid Flow in Geothermal Energy Piles. MS thesis, Virginia Polytechnic Institute and State University, Blacksburg, VA, USA.

Wang ZJ, Xie XY and Wang JC (2012) A new nonlinear method for vertical settlement prediction of a single pile and pile groups in layered soils. Computers and Geotechnics 45: 118-126, https://doi. org/10.1016/j.compgeo.2012.05.011.

Wang C, Liu H, Kong G, Ng C and Wu D (2016) Model tests of energy piles with and without a vertical load. Environmental Geotechnics 3(4): 203-213, https://doi.org/10.1680/jenge. 15.00020 .

Wang Z, Zhang R, Wang K et al. (2019) Analysis for bearing characteristics of the static drill rooted pile considering the condition of energy carrier. Journal of Zhejiang University (Engineering Science) 53(1): 11-18, https://doi.org/10.3785/j.issn.1008-973X.2019. 01.002 .

Yavari N, Tang AM, Pereira JM and Hassen G (2014) A simple method for numerical modelling of mechanical behaviour of an energy pile. Géotechnique Letters 4(2): 119-124, https://doi.org/10.1680/geolett. 13.00053.

Zarrella A, Emmi G, Zecchin R and Di Carli M (2017) An appropriate use of the thermal response test for the design of energy foundation piles with U-tube circuits. Energy and Buildings 134: 259-270, https://doi. org/10.1016/j.enbuild.2016.10.053.

Zhang W, Yang H, Fang L et al. (2017) Study on heat transfer of pile foundation ground heat exchanger with three-dimensional groundwater seepage. International Journal of Heat and Mass Transfer 105: 58-66, https://doi.org/10.1016/j.ijheatmasstransfer.2016. 09.066 .

Zhang Q, Feng R, Liu S et al. (2018) Estimation of uplift capacity of a single pile embedded in sand considering arching effect. International Journal of Geomechanics 18(9): 06018021.

Zhou H, Kong GQ, Liu HL et al. (2018) Similarity solution for cavity expansion in thermoplastic soil. International Journal for Numerical and Analytical Methods in Geomechanics 42(2): 274-294.

\section{How can you contribute?}

To discuss this paper, please submit up to 500 words to the editor at journals@ice.org.uk. Your contribution will be forwarded to the author(s) for a reply and, if considered appropriate by the editorial board, it will be published as a discussion in a future issue of the journal. 